\title{
Geriatric assessment in older patients with a hematologic malignancy: a systematic review
}

\author{
Ellen R.M. Scheepers, ${ }^{1}$ Ariel M. Vondeling, ${ }^{2}$ Noortje Thielen, ${ }^{1}$ René van der \\ Griend, ${ }^{1}$ Reinhard Stauder ${ }^{3}$ and Marije E. Hamaker ${ }^{2}$
}

${ }^{1}$ Department of Internal Medicine, Diakonessenhuis Utrecht, Utrecht, the Netherlands; ${ }^{2}$ Department of Geriatric Medicine, Diakonessenhuis Utrecht, Utrecht, the Netherlands and ${ }^{3}$ Department of Internal Medicine V (Hematology and Oncology), Innsbruck Medical University, Innsbruck, Austria

Haematologica 2020

Volume 105(6):1484-1493

\section{Correspondence: \\ ELLEN.R.M. SCHEEPERS \\ escheepers@diakhuis.nl \\ Received: December 24, 2019. \\ Accepted: April 2, 2020. \\ Pre-published: May 7, 2020.}

doi:10.3324/haematol.2019.245803

Check the online version for the most updated information on this article, online supplements, and information on authorship \& disclosures: www.haematologica.org/content/105/6/1484

(C)2020 Ferrata Storti Foundation

Material published in Haematologica is covered by copyright. All rights are reserved to the Ferrata Storti Foundation. Use of published material is allowed under the following terms and conditions:

https://creativecommons.org/licenses/by-nc/4.0/legalcode. Copies of published material are allowed for personal or internal use. Sharing published material for non-commercial purposes is subject to the following conditions:

https://creativecommons.org/licenses/by-nc/4.0/legalcode, sect. 3. Reproducing and sharing published material for commercial purposes is not allowed without permission in writing from the publisher.

\section{ABSTRACT}

T he aim of this systematic review is to give an update of all currently available evidence on the relevance of a geriatric assessment in the treatment of older patients with hematologic malignancies. A systematic search in MEDLINE and EMBASE was performed to find studies in which a geriatric assessment was used to detect impaired geriatric domains or to address the association between geriatric assessment and survival or clinical outcome measures. The literature search included 4,629 reports, of which 54 publications from 44 studies were included. Seventy-three percent of the studies were published in the last 5 years. The median age of the patients was 73 years (range, 58-86) and $71 \%$ had a good World Health Organization (WHO) performance status. The median prevalence of geriatric impairments varied between $17 \%$ and $68 \%$, even in patients with a good WHO performance status. Polypharmacy, nutritional status and instrumental activities of daily living were most frequently impaired. Whereas several geriatric impairments and frailty (based on a frailty screening tool or summarized geriatric assessment score) were predictive for a shorter overall survival, WHO performance status lost its predictive value in most studies. The association between geriatric impairments and treatment-related toxicity varied, with a trend towards a higher risk of (non-)hematologic toxicity in frail patients. During the follow-up, frailty seemed to be associated with treatment non-completion, especially when patients were malnourished. Patients with a good physical capacity had a shorter stay in hospital and a lower rate of hospitalization. Geriatric assessment, even in patients with a good performance status, can detect impaired geriatric domains and these impairments may be predictive of mortality. Moreover, geriatric impairments suggest a higher risk of treatment-related toxicity, treatment non-completion and use of healthcare services. A geriatric assessment should be considered before starting treatment in older patients with hematologic malignancies.

\section{Introduction}

Given the increasing life expectancy and aging of the population, there is a growing number of older patients with cancer, including patients with a hematologic malignancy. Worldwide, hematologic malignancies account for approximately 9\% of all cancers and are the fourth most frequently diagnosed cancer. ${ }^{1}$ At present, $60 \%$ of these patients are older than 65 years and this proportion will increase in the future. ${ }^{2,3}$

Over the last decades, treatment options for hematologic malignancies have progressed. For example, the initial treatment of patients with multiple myeloma changed from cytotoxic chemotherapeutics to better-tolerated agents such as immuno-modulatory drugs or monoclonal antibodies. ${ }^{4}$ Moreover, the proportion of older patients with myelodysplastic syndrome or acute myeloid leukemia undergoing hematopoietic stem cell transplantation has increased, partly due to expansion of age limits. ${ }^{5,6}$ 
However, it can be difficult to deliver optimal cancer treatment tailored to individual needs of an older patient, particularly as older patients are frequently excluded from clinical trials. ${ }^{7}$ Older patients constitute a heterogeneous population due to large differences in comorbidity, functional capacity and psychological and physical reserves. As a result, the benefit of treatment can differ and patients with comorbidity or geriatric impairments are particularly at risk of adverse health outcomes. Choosing the optimal treatment for these patients is a challenge.

It is therefore recommended that the degree of frailty of older patients is assessed. ${ }^{8}$ Frailty is a biological syndrome which can exist alongside age, comorbidity or disease characteristics. Over the years, numerous definitions of frailty have been formulated and there is still no consensus on a definition. ${ }^{9}$ There are two commonly used approaches to define frailty. The first defines frailty based on phenotypic criteria including reduced grip strength, walking speed, physical capacity, level of energy and weight loss. Patients are considered frail if three or more criteria are present. ${ }^{10}$ The second approach proposes a frailty index which is an accumulation of patient's deficits. These deficits consist of physical or cognitive symptoms, functional impairments, abnormal laboratory values and comorbidities. ${ }^{11,12}$ In daily practice, frailty is a dynamic state which needs a multidimensional approach and might have various implications in different scenarios.

An appropriate method to assess the level of frailty of older patients is a geriatric assessment. ${ }^{8,13}$ This consists of a systematic assessment of an older patient's health status focusing on somatic, psychological, functional and social domains. Different tools can be used to detect geriatric impairments in these domains. ${ }^{14}$ Moreover, frailty screening tools were developed in order to identify older patients who require a full geriatric assessment. ${ }^{15}$ Nowadays, some form of geriatric assessment is increasingly incorporated in hemato-oncologic care to customize hemato-oncologic treatment. ${ }^{16}$

In 2014, we published a systematic review on the value of performing a geriatric assessment in older patients with a hematologic malignancy, demonstrating that such an assessment can detect multiple health issues and has predictive value for clinical outcome in older patients with a hematologic malignancy. ${ }^{17}$ However, evidence was limited, especially regarding clinical outcomes such as treatmentrelated toxicity, treatment completion or physical functioning after treatment. Since then, many new studies have been published on this subject. The aim of this present systematic review is, therefore, to give an update of all currently available data on the association between geriatric impairments and hematologic cancer-related outcomes.

\section{Methods}

\section{Search strategy and article selection}

Our aim was to identify studies concerning patients with a hematologic malignancy in which a geriatric assessment was used to detect geriatric impairments or which addressed the association between baseline geriatric assessment and outcome.

Geriatric assessment was defined as an assessment composed of at least two of the following domains: cognitive function, mood, nutritional status, activities of daily living (ADL), instrumental activities of daily living (IADL), polypharmacy (using five or more drugs), objectively measured physical capacity (for instance, gait speed, hand grip strength or balance tests), social support and frailty (assessed with a frailty screening tool or by summarizing the geriatric assessment). As prior medical history/comorbidity and performance status are routine parts of the hematologic work-up, these were not counted as domains of the geriatric assessment for this particular systematic review. The following items were defined as outcomes: prevalence of geriatric impairments, change in oncologic treatment plan, toxicity of chemotherapy, healthcare utilization, physical functioning after treatment, quality of life after treatment and mortality.

The following search was performed on March 4, 2019 and updated on January 20, 2020, in both MEDLINE and EMBASE: ((("Hematologic Neoplasms"[Mesh] OR "Leukemia"[Mesh] OR "Lymphoma"[Mesh] OR "Multiple Myeloma"[Mesh] OR "Myelodysplastic Syndromes"[Mesh] OR leukemia[tiab] OR leukaemia[tiab] OR lymphoma*[tiab] OR hodgkin*[tiab] OR nonhodgkin*[tiab] OR (multiple myeloma[tiab]) OR myelodysplas*[tiab] OR (haematolog* AND malignan*[tiab]) OR (hematolog* AND malignan*[tiab]) OR (myeloid[tiab] OR lymphoid[tiab] AND neoplas*[tiab]) OR myeloproliferative[tiab] OR (plasma cell neoplas*[tiab]) OR plasma cell dyscrasia*[tiab] OR (myeloid[tiab] AND sarcoma*[tiab]) OR waldenstrom[tiab] OR myelofibrosis[tiab] OR mastocystosis[tiab] OR (polycyth* AND vera[tiab]) OR (essential AND thrombocyt*[tiab]))) AND (("frailty"[All Fields] OR "Geriatric Assessment"[Mesh] OR frail*[tiab] OR vulnerabl*[tiab] OR geriatric assessment*[tiab] OR geriatric*[tiab]))

No age or language limitations were applied. All search results until 2013 were reviewed previously by Hamaker et al. ${ }^{17} \mathrm{We}$ therefore limited our search to studies published after January 1 , 2013. The titles and abstracts of all studies retrieved by the search were assessed by one reviewer (ES) to determine which warranted further examination. The full texts of all potentially relevant articles were subsequently screened. We excluded studies that did not focus exclusively on hematologic malignancies. Finally, references of included studies were cross-referenced to retrieve any additional relevant citations. Eligible studies from all searches $(2013,2019,2020)$ were subsequently combined to form the final study selection.

\section{Data extraction}

For each eligible study, data regarding study design and results were independently extracted by two authors (ES and AV). Extracted items included the type of study, study population (number of patients, median age, malignancy subtype, stage, treatment) and the content of the geriatric assessment. Only validated tools from the geriatric assessment were included. If multiple tools were used to assess one geriatric domain, the result of the most commonly used tool was noted. We registered the prevalence of geriatric impairments, and the reported results on the association between the geriatric assessment and outcome measures. If necessary, study authors were contacted to obtain additional data.

\section{Quality assessment}

The methodological quality of each of the studies was assessed independently by two reviewers (ES and AV), using the Newcastle-Ottawa scale adapted to this subject (Online Supplementary Table S1). ${ }^{18}$ As our main focus was on older patients with hematologic malignancies, we classified studies of patients with a me(di)an age less than 68 years old, or with more than one third of the patients younger than 65 years old, as not being fully representative of our target population. Disagreements among the reviewers were discussed during a consensus meeting and in the case of persisting disagreement, the assistance of a third reviewer $(\mathrm{MH})$ was enlisted. 


\section{Data synthesis and analysis}

Due to the heterogeneity in the populations of patients and in study designs, with a wide variety in content of geriatric assessments, a meta-analysis was not considered feasible. We therefore summarized the study results to describe our main outcomes of interest.

\section{Results}

\section{Study characteristics}

The literature search yielded 4,629 citations (832 from MEDLINE and 3,797 from EMBASE), of which 403 were duplicates and 4,184 were excluded for other reasons
(Online Supplementary Figure S1). This resulted in 42 eligible publications from 34 studies. Cross-referencing yielded four additional publications. Eight publications from the 2014 review by Hamaker et al. ${ }^{17}$ were also eligible. Thus, we ultimately included 54 publications from 44 studies in this review. ${ }^{19-72}$

The characteristics of these 44 studies are summarized in Table 1. Seventy-three percent were published in the last 5 years. The median sample size of the studies was 100 (range, 25-869), and the me(di)an age of included patients ranged from 58 to 86 years. Eight studies focused on acute myeloid leukemia and/or myelodysplastic syndromes, ${ }^{19-25,27}$ two on chronic lymphocytic leukemia, ${ }^{28,29}$ 13 on lymphoma, ${ }^{30-42}$ seven on multiple myeloma, ${ }^{42-48}$ and

Table 1. Characteristics of studies on the association between the geriatric assessment and outcome measures.

\begin{tabular}{|c|c|c|c|c|c|c|c|c|c|c|c|}
\hline \multicolumn{2}{|l|}{ Publication } & \multirow[b]{2}{*}{$\begin{array}{c}\text { Patient } \\
\text { population }\end{array}$} & \multicolumn{2}{|c|}{ Study population } & \multirow[b]{2}{*}{$\begin{array}{l}\text { Me(di)an } \\
\text { age* }^{*}\end{array}$} & \multirow[b]{2}{*}{ Treatment } & \multicolumn{2}{|c|}{ GA } & \multicolumn{3}{|c|}{ Outcome measures } \\
\hline Author & Year & & $\begin{array}{l}\text { Type of } \\
\text { malignancy }\end{array}$ & $\begin{array}{c}\text { N. of } \\
\text { patients }\end{array}$ & & & $\begin{array}{c}\text { N. of } \\
\text { domains } \\
\text { assessed }\end{array}$ & $\begin{array}{l}\text { Summarized } \\
\text { GA score }\end{array}$ & $\begin{array}{l}\text { Prevalence } \\
\text { of geriatric } \\
\text { conditions }\end{array}$ & Survival & Other \\
\hline Aguiar $^{19}$ & 2020 & $65+$ & MDS & 79 & 77 (70-84) & $\begin{array}{l}\text { No disease- } \\
\text { modifying } \\
\text { therapy }\end{array}$ & 3 & & + & & \\
\hline Corsetti $^{20}$ & 2013 & $\begin{array}{l}\text { 65+ or unfit for } \\
\text { aggressive CT }\end{array}$ & AML; RAEB & 31 & $72(55-84)$ & CT & 2 & + & + & + & \\
\hline Deschler $^{21}$ & 2013 & $60+$ & AML; MDS & 195 & $71(60-87)$ & $\mathrm{BSC} ; \mathrm{CT}$ & 5 & & + & + & \\
\hline Holmes $^{22}$ & 2014 & $60+$ & AML; MDS & 50 & $65(60-73)$ & HSCT & 8 & + & + & & \\
\hline Klepin $^{23}$ & 2013 & $60+$ & AML & 74 & $68(65-74)$ & CT & 5 & & + & + & \\
\hline Klepin $^{24}$ & 2020 & $60+$ & AML (FLT3) & 40 & 68 (61-83) & CT & 7 & & + & + & \\
\hline Molga $a^{25,26}$ & 2020 & $65+$ & AML; MDS & 98 & $77(66-95)$ & $\mathrm{BSC} ; \mathrm{CT}$ & 7 & & + & + & Treatment completion \\
\hline Umit $^{27}$ & 2018 & no age limit & AML & 372 & $63(19-97)$ & CT & 4 & & + & + & \\
\hline Goede $^{28}$ & 2016 & no age limit & CLL & 75 & $75(48-87)$ & CT & 3 & & + & + & Toxicity \\
\hline Molica ${ }^{29}$ & 2019 & $65+$ & CLL & 108 & $71(65-90)$ & CT & 2 & + & + & + & Toxicity \\
\hline $\operatorname{Ribi}^{30}$ & 2017 & no age limit & B-cell lymphoma & 41 & $75(40-94)$ & Various & 4 & + & + & + & \\
\hline Merli $^{31}$ & 2020 & $65+$ and unfit & DLBCL & 33 & $82(68-89)$ & CT & 2 & & + & & \\
\hline Ong ${ }^{32}$ & 2019 & $60+$ & DLBCL & 205 & $73(60-97)$ & CT & 2 & + & + & + & $\begin{array}{l}\text { Health care utilization, } \\
\text { toxicity, treatment } \\
\text { completion }\end{array}$ \\
\hline Spina $^{33}$ & 2012 & $70+$ & DLBCL & 100 & $75(70-89)$ & CT & 4 & + & + & + & Toxicity \\
\hline Tucci $^{34}$ & 2009 & $65+$ & DLBCL & 84 & $73(66-89)$ & CT & 1 & + & + & + & Toxicity \\
\hline Tucci $^{35}$ & 2015 & $69+$ & DLBCL & 173 & 77 & Various & 2 & + & + & + & \\
\hline Aaldriks $^{36}$ & 2015 & $70+$ & NHL & 44 & $78(70-86)$ & CT & 3 & & + & + & Treatment completion \\
\hline Naito $^{37}$ & 2016 & $65+$ & NHL & 93 & $77(65-90)$ & Various & 5 & & + & + & Toxicity \\
\hline Park $^{38}$ & 2015 & $65+$ & NHL & 70 & $74(65-92)$ & CT & 4 & & + & + & Treatment completion \\
\hline Siege ${ }^{39}$ & 2006 & $60+$ & NHL & 25 & $70(60-85)$ & $?$ & 3 & & + & & \\
\hline Soubeyran ${ }^{40}$ & 2011 & $\begin{array}{l}\text { 70+, unfit for } \\
\text { aggressive CT }\end{array}$ & NHL & 32 & $79(70-92)$ & CT & 4 & & + & + & \\
\hline Winkelmann $n^{41}$ & 2011 & $18+$ & NHL & 143 & $63(18-88)$ & CT & 2 & & + & + & \\
\hline Okuyama $^{42}$ & 2015 & $65+$ & Lymphoma; MM & 106 & $74(65-90)$ & CT & 5 & + & + & & \\
\hline Engelhardt ${ }^{43}$ & 2016 & no age limit & MM & 125 & $63(56-71)$ & CT & 2 & & + & + & \\
\hline Gavriatopoulou & 442019 & $80+$ & MM & 110 & $83(80-92)$ & CT & 3 & & + & + & \\
\hline Palumb ${ }^{45}$ & 2015 & $70+$ & MM & 869 & $74(70-78)$ & CT & 2 & + & + & + & $\begin{array}{l}\text { Toxicity, Treatment } \\
\text { completion }\end{array}$ \\
\hline Rosko $0^{46}$ & 2019 & $18+$ & MM; amyloidosis & 100 & $59(36-75)$ & HSCT & 6 & & + & & Health care utilization \\
\hline Wildes $^{47}$ & 2019 & $65+$ & MM & 40 & $71(66-76)$ & BSC;HSCT & 5 & & + & & \\
\hline Zhong ${ }^{48}$ & 2017 & no age limit & MM & 628 & $58(52-66)$ & CT & 2 & + & + & + & $\begin{array}{l}\text { Toxicity } \\
\text { continued of }\end{array}$ \\
\hline
\end{tabular}


continued from the previous page

\begin{tabular}{|c|c|c|c|c|c|c|c|c|c|c|c|}
\hline Buckstein $^{49}$ & 2016 & $65+$ & Various & 445 & $71(65-79)$ & CT & 3 & & + & + & \\
\hline Deschler $^{50}$ & 2018 & $60+$ & Various & 106 & $66(60-78)$ & HSCT & 5 & & + & + & \\
\hline Derman $^{51}$ & 2019 & $60+$ & Various & 192 & $>67(60-83)$ & HSCT & 5 & & + & & \\
\hline Dubruille ${ }^{52}$ & 2015 & $65+$ & Various & 90 & $74(65-89)$ & CT & 8 & + & + & + & \\
\hline Dumontier $^{53}$ & 2019 & $75+$ & Various & 464 & $80(76-84)$ & BSC; CT & 3 & & + & + & Health care utilization \\
\hline Hamaker $^{54}$ & 2016 & $65+$ & Various & 157 & $78(67-99)$ & Various & 7 & + & + & + & \\
\hline Huang $g^{55}$ & 2020 & $50+$ & Various & 148 & $62(50-76)$ & HSCT & 6 & & + & + & $\begin{array}{l}\text { Health care utilization, } \\
\text { toxicity }\end{array}$ \\
\hline $\operatorname{Lin}^{56}$ & 2020 & $60+$ & Various & 457 & $66(60-79)$ & HSCT & 5 & & + & + & \\
\hline $\mathrm{Liu}^{57}$ & 2019 & $75+$ & Various & 448 & $80(76-84)$ & BSC; CT & 2 & + & + & + & Health care utilization \\
\hline Muffly $y^{58}$ & 2014 & $50+$ & Various & 203 & $58(54-63)$ & HSCT & 3 & + & + & + & \\
\hline Nawas $^{59}$ & 2019 & $50+$ & Various & 184 & $61(50-75)$ & HSCT & 5 & & + & + & $\begin{array}{l}\text { Health care utilization, } \\
\text { toxicity }\end{array}$ \\
\hline Rodrigues $^{60}$ & 2020 & $60+$ & Various & 40 & $68(60-76)$ & HSCT & 6 & + & + & & \\
\hline Rollot-Trad ${ }^{61}$ & 2008 & $\begin{array}{c}75+\text {, geriatric } \\
\text { department }\end{array}$ & Various & 54 & $86(75-99)$ & Various & 4 & & + & + & \\
\hline Silay $^{62}$ & 2015 & $65+$ & Various & 61 & 69 & $?$ & 7 & & + & & Health care utilization \\
\hline Velghe $^{63}$ & 2014 & $70+$ & Various & 50 & $76(70-87)$ & Various & 6 & + & + & & \\
\hline
\end{tabular}

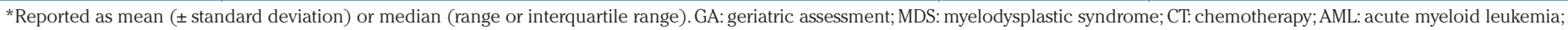
RAEB: refractory anemia with excess of blasts; FLT3: FMS like tyrosine kinase-3; BSC: best supportive care; HSCT: hematopoietic stem cell transplantation; CLL: chronic lymphocytic leukemia; DLBCL: diffuse large B-cell lymphoma; NHL: non-Hodgkin lymphoma; MM: multiple myeloma.

15 studies included various hematologic malignancies. ${ }^{49-63}$

The median number of domains addressed in the geriatric assessment was four (range, 2-9). These included ADL in 30 studies (68\%), IADL in $37(84 \%)$, cognition in $29(66 \%)$, mood in $24(55 \%)$ and objectively measured physical capacity in 20 studies (46\%). Domains less commonly assessed were nutritional status (11 studies; $25 \%$ ), social support (8 studies; $18 \%$ ), polypharmacy (13 studies; $30 \%$ ) and frailty (8 studies assessed with a frailty screening tool and 17 studies by summarizing the geriatric assessment; $18 \%$ and $39 \%$, respectively).

The prevalence of geriatric impairments was assessed in all studies $(100 \%)$. The association between geriatric impairments and mortality was addressed in 33 studies $(75 \%)$, treatment-related toxicity in ten studies $(23 \%)$, treatment completion in five $(11 \%)$ and healthcare utilization in seven studies (16\%). No studies assessed the association of geriatric impairments with physical functioning or quality of life after treatment.

\section{Quality assessment}

The results of the quality assessment are shown in Figure 1. Detailed results per study are listed in Online Supplementary Table S1. The overall quality of the studies was good. Nine studies included a significant proportion of younger patients (i.e. median age less than 68 years old, or more than one third of the patients younger than 65 years old); $22,27,41,43,46,48,50,58,59$ these studies were assessed as not being fully representative of the target cohort of the average older patients with a hematologic malignancy. Similarly, eight studies focused on a very specific treatment $\mathrm{t}^{20,23,24,31,51,55,56,60}$ which we considered as not fully representative of our target population. Overall, the duration of follow-up was sufficient but in nine studies the followup rate was less than $90 \%{ }^{24,30,46}$ or the adequacy of followup was not reported. . $732,33,56,57,62$ There were no other quality concerns.

\section{Prevalence of geriatric impairments}

The prevalence of geriatric impairments is shown in Table 2. The most commonly reported issues were polypharmacy (in a median of $51 \%$ of patients; range, 17 $80 \%$ ), risk of malnutrition (median $44 \%$; range, $27-82 \%$ ) and IADL impairments (median 37\%; range, 3-85\%). Impaired physical capacity (median $27 \%$; range, 3-80\%), ADL impairments (median 18\%; range, 4-67\%), symptoms of depression (median 25\%; range, 10-94\%), and cognitive impairment (median 17\%; range, 0-44\%) were less common. Four studies that addressed social support showed impairment in a median of $20 \%$ (range, $7-54 \%$ ). The median proportion of patients seen as frail based on a frailty screening tool was $68 \%$ (range, $25-76 \%$ ). The median proportion of patients screened as frail based on a summarized geriatric assessment score was 45\% (range, 10-88\%).

Overall, the median proportion of patients with at least one geriatric impairment was $51 \%$ (range, 9-82\%). By comparison, the median proportion of patients with a World Health Organization (WHO) performance status of 2 or higher was only $29 \%$ (range, 1-91\%). Even in studies in which the median age of patients was $\leq 65$ years old, or a small proportion of patients had a poor WHO performance status, geriatric impairments were quite common. For example, in one study, $93 \%$ of included patients had a WHO performance status of $0-1$; nonetheless, $45 \%$ of patients had impairments in IADL, 39\% in physical capacity and $25 \%$ were frail based on a frailty screening tool (Table 2). ${ }^{49}$

\section{Association between geriatric impairments and mortality}

The association of geriatric impairments with mortality was addressed in 33 studies (Table 3 ). In univariate analysis, 27 out of 29 studies (93\%) showed a significant association between at least one geriatric impairment and mortality. The association between a specific geriatric domain and mortality varied between 0 and $74 \%$. 
Representiveness of exposed cohort

Ascertainment of exposure (GA)

Outcome not present at start of study

Assessment of outcome

Sufficient duration of follow up

Adequacy of follow up

Low risk of bias

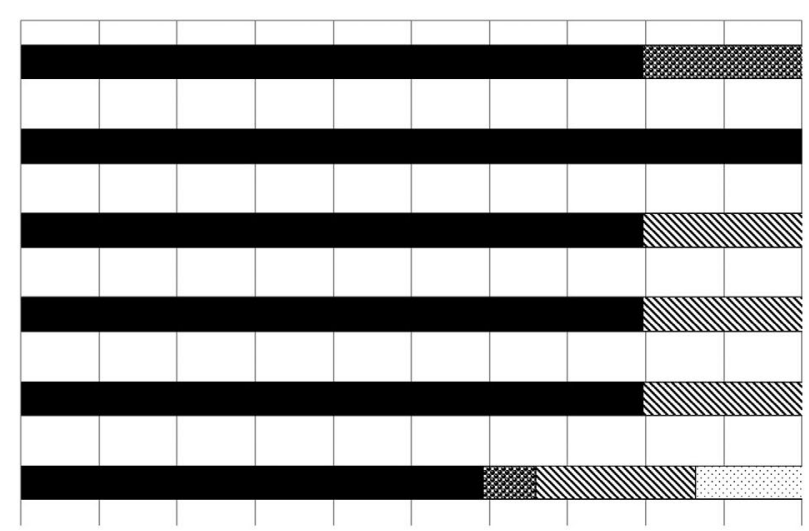

High risk of bias $\mathbb{\$}$ Not applicable
Unknown risk of bias

Figure 1. Outcome of the quality assessment. Details are reported in Online Supplementary Table S1A (quality assessment questionnaire) and Online Supplementary Table S1B (assessment per study).

Polypharmacy was assessed in only two studies and showed no association. For all other geriatric domains except mood, nutritional status and social support, at least $50 \%$ of the studies reported a univariate association between impairment and mortality. IADL, ADL, impaired physical capacity and cognition were most frequently associated with mortality (in $74 \%, 67 \%, 63 \%$ and $55 \%$ of the studies, respectively). In multivariable analyses, $\mathrm{ADL}$, IADL, impaired physical capacity and cognition remained associated with mortality (in $40 \%, 62 \%, 50 \%$ and $50 \%$ of the studies, respectively). Moreover, at least $75 \%$ of all studies that assessed frailty (with a frailty screening tool or by summarizing the geriatric assessment), demonstrated that this was associated with mortality in multivariable analyses.

Risk factors for mortality commonly used in hematooncology such as age, WHO performance status and comorbidity were also associated with mortality in univariate analysis (in $79 \%, 63 \%$ and $64 \%$ of the studies, respectively). However, in multivariable analyses, this association was no longer present for WHO performance status; age and comorbidity retained their association with mortality in $43 \%$ and $47 \%$ of the studies, respectively.

\section{Association of geriatric impairments with treatment- related toxicity}

Ten studies assessed geriatric impairments in relation to treatment-related toxicity. ${ }^{28,29,32-34,37,45,48,55,59}$ Four out of six studies in which frailty was assessed (based on a summarized geriatric assessment score) reported an association between frailty and treatment-related toxicity. ${ }^{33,34,45,48}$ This included hematologic toxicity in one study, ${ }^{33}$ non-hematologic toxicity in two studies ${ }^{45,48}$ and overall toxicity in one study. ${ }^{34}$ One study showed an association specifically between impaired IADL and treatment-related infections in patients with chronic lymphocytic leukemia. ${ }^{28}$ In studies in which patients with various hematologic malignancies were included, associations between physical capacity $^{55}$ or cognition ${ }^{59}$ and treatment-related toxicity were demonstrated. No other associations between frailty (based on a summarized geriatric assessment score) or individual geriatric domains and treatment-related toxicity were found in these ten studies.

\section{Association of geriatric impairments with treatment completion}

The association of geriatric impairments with the ability to complete the proposed treatment was studied in five studies. ${ }^{25,32,36,38,45}$ Four out of five studies found an association between geriatric impairments and treatment completion. The risk of treatment non-completion was significantly higher in frail patients (based on a summarized geriatric assessment score or frailty screening tool) than in fit patients. ${ }^{25,36,38,45}$ Three studies showed a significant association between a specifically geriatric domain and treatment non-completion: in two studies that included patients with non-Hodgkin lymphoma, malnutrition was associated with treatment non-completion. ${ }^{36,38}$ Another study, in which patients with acute myeloid leukemia or myelodysplastic syndrome were included, showed an association between impaired IADL, impaired physical capacity or cognitive impairment and treatment non-completion. In this study, no other geriatric impairments or clinical characteristics such as comorbidity or WHO performance status were associated with treatment non-completion. ${ }^{25}$

\section{Association of geriatric impairments with healthcare utilization}

The association of geriatric impairments and health care utilization was addressed in seven studies. ${ }^{32,46,53,55,57,59,62}$ Six out of these studies showed an association between geriatric impairments and health care utilization. In four studies impaired physical capacity was associated with increased use of health care. ${ }^{46,55,57,62}$ In patients with various hematologic malignancies, other geriatric impairments, such as ADL, ${ }^{62}$ IADL $^{53}$ cognition ${ }^{59}$ and mood $^{46}$ were also associated with health care utilization. In one study with patients with diffuse large B-cell lymphoma, no association was found between frailty (assessed by a summarized geriatric assessment score) and unplanned admissions. ${ }^{32}$ 
Table 2. Comparison of impaired performance status with impairments in geriatric domains.

\begin{tabular}{|c|c|c|c|c|c|c|c|c|c|c|c|c|c|c|c|}
\hline Author & Year & $\begin{array}{c}\text { Type of } \\
\text { malignancy }\end{array}$ & $\mathbf{N}$ & $\begin{array}{c}\text { Me(di)an } \\
\text { age* }\end{array}$ & $\begin{array}{c}\text { Poor } \\
\text { PS }\end{array}$ & ADL & IADL & Cognition & Mood & $\begin{array}{l}\text { Physical } \\
\text { capacity }\end{array}$ & $\begin{array}{l}\text { Nutritional } \\
\text { status }\end{array}$ & $\begin{array}{l}\text { Social } \\
\text { support }\end{array}$ & $\begin{array}{c}\text { Poly- } \\
\text { pharmacy }\end{array}$ & $\begin{array}{l}\text { Fraility } \\
\text { screening } \\
\text { tool }\end{array}$ & $\begin{array}{l}\text { Summarised } \\
\text { GA score }\end{array}$ \\
\hline Aguiar ${ }^{19}$ & 2020 & MDS & 76 & $77(70-84)$ & - & - & - & - & - & $80 \%$ & - & - & $61 \%$ & $38 \%$ & - \\
\hline Corsetti $^{20}$ & 2013 & AML; RAEB & 31 & $72(55-84)$ & $38 \%$ & $17 \%$ & $59 \%$ & - & - & - & - & - & - & - & $54 \%$ \\
\hline Deschler $^{21}$ & 2013 & AML; MDS & 195 & $71(60-87)$ & $47 \%$ & $34 \%$ & $31 \%$ & $9 \%$ & $14 \%$ & $55 \%$ & - & - & - & - & - \\
\hline Holmes ${ }^{22}$ & 2014 & AML; MDS & 50 & $65(60-73)$ & $12 \%$ & \multicolumn{2}{|c|}{$16 \%$} & $16 \%$ & $10 \%$ & $18 \%$ & $36 \%$ & $54 \%$ & $>28 \%$ & - & $66 \%$ \\
\hline Klepin $^{23}$ & 2013 & AML & 74 & $68(65-74)$ & $22 \%$ & $50 \%$ & $41 \%$ & $29 \%$ & $40 \%$ & $50 \%$ & - & - & - & - & - \\
\hline Klepin $^{24}$ & 2020 & AML (FLT3) & 40 & $68(61-83)$ & $?$ & $?$ & $?$ & $?$ & $?$ & $56 \%$ & - & $?$ & $36 \%$ & - & - \\
\hline Molga ${ }^{25,26}$ & 2020 & AML; MDS & 98 & $77(66-95)$ & $28 \%$ & $29 \%$ & $34 \%$ & $11 \%$ & $32 \%$ & $31 \%$ & $27 \%$ & - & - & $68 \%$ & - \\
\hline Umit $^{27}$ & 2018 & AML & 372 & $63(19-97)$ & $91 \%$ & - & $80 \%$ & $14 \%$ & $79 \%$ & - & - & - & - & $70 \%$ & - \\
\hline Goede $^{28}$ & 2016 & CLL & 75 & $75(48-87)$ & $?$ & - & $19 \%$ & $29 \%$ & - & $48 \%$ & - & - & - & - & - \\
\hline Molica $^{29}$ & 2019 & CLL & 108 & $71(65-90)$ & $?$ & $16 \%$ & $19 \%$ & - & - & - & - & - & - & - & $10 \%$ \\
\hline $\operatorname{Ribi}^{30}$ & 2017 & B-cell lymphoma & 41 & $75(40-94)$ & $15 \%$ & - & - & $27 \%$ & $20 \%$ & - & $73 \%$ & $7 \%$ & - & - & $39 \%$ \\
\hline Merli $^{31}$ & 2020 & DLBCL & 33 & $85(68-89)$ & $6 \%$ & $18 \%$ & $3 \%$ & - & - & - & - & - & - & - & - \\
\hline $\mathrm{Ong}^{32}$ & 2019 & DLBCL & 205 & $73(60-97)$ & $7 \%$ & $7 \%$ & $36 \%$ & - & - & - & - & - & - & - & $38 \%$ \\
\hline Spina $^{33}$ & 2012 & DLBCL & 100 & 75 (70-89) & $26 \%$ & $27 \%$ & $31 \%$ & $?$ & $?$ & - & - & - & - & - & $13 \%$ \\
\hline Tucci $^{34}$ & 2009 & DLBCL & 84 & 73 (66-89) & $?$ & $12 \%$ & - & - & - & - & - & - & - & - & $50 \%$ \\
\hline Tucci $^{35}$ & 2015 & DLBCL & 173 & 77 & $?$ & $\begin{array}{l}>4 \% \\
<54 \%\end{array}$ & $\begin{array}{l}>9 \% \\
<54 \%\end{array}$ & - & - & - & - & - & - & - & $38 \%$ \\
\hline Aaldriks ${ }^{36}$ & 2015 & NHL & 44 & $78(70-86)$ & $6 \%$ & - & - & $5 \%$ & - & - & $34 \%$ & - & - & $43 \%$ & - \\
\hline Naito $^{37}$ & 2016 & NHL & 93 & $77(65-90)$ & $22 \%$ & $28 \%$ & $27 \%$ & $4 \%$ & $15 \%$ & - & $51 \%$ & - & - & - & - \\
\hline Park $^{38}$ & 2015 & NHL & 70 & $74(65-92)$ & $39 \%$ & - & - & $37 \%$ & $21 \%$ & - & $36 \%$ & - & - & $47 \%$ & - \\
\hline Siege $^{39}$ & 2006 & NHL & 25 & $70(60-85)$ & $12 \%$ & - & - & $0 \%$ & $16 \%$ & $12 \%$ & - & - & - & - & - \\
\hline Soubeyran ${ }^{40}$ & 2011 & NHL & 32 & $79(70-92)$ & $41 \%$ & $59 \%$ & $81 \%$ & $38 \%$ & $94 \%$ & - & - & - & - & - & - \\
\hline Winkelmann $n^{41}$ & 2011 & NHL & 143 & $63(18-88)$ & $16 \%$ & $18 \%$ & $21 \%$ & - & - & - & - & - & - & - & - \\
\hline Okuyama $^{42}$ & 2015 & Lymphoma; MM & 106 & $74(65-90)$ & $29 \%$ & $33 \%$ & $45 \%$ & $23 \%$ & $30 \%$ & - & - & - & $17 \%$ & - & $50 \%$ \\
\hline Engelhardt $t^{43}$ & 2016 & MM & 125 & $63(56-71)$ & $28 \%$ & $48 \%$ & $85 \%$ & - & - & - & - & - & - & - & - \\
\hline Gavriatopoulou ${ }^{44}$ & ${ }^{4} 2019$ & MM & 110 & $83(80-92)$ & $>60 \%$ & $18 \%$ & $42 \%$ & - & - & - & - & - & - & $73 \%$ & - \\
\hline Palumbo ${ }^{45}$ & 2015 & MM & 869 & $74(70-78)$ & $21 \%$ & $14 \%$ & $18 \%$ & - & - & - & - & - & - & - & $30 \%$ \\
\hline Rosko $0^{46}$ & 2019 & MM; amyloidosis & 100 & $59(36-75)$ & $48 \%$ & $?$ & $?$ & $?$ & $19 \%$ & $7 \%$ & - & $?$ & - & - & - \\
\hline Wildes $^{47}$ & 2019 & MM & 40 & $71(66-76)$ & $40 \%$ & - & $63 \%$ & $10 \%$ & $?$ & $40 \%$ & - & - & $77 \%$ & - & - \\
\hline Zhong ${ }^{48}$ & 2017 & MM & 628 & $58(52-66)$ & $?$ & $67 \%$ & $55 \%$ & - & - & - & - & - & - & - & $64 \%$ \\
\hline Buckstein $^{49}$ & 2016 & Various & 445 & $71(65-79)$ & $7 \%$ & - & $45 \%$ & - & - & $39 \%$ & - & - & - & $25 \%$ & - \\
\hline Deschler $^{50}$ & 2018 & Various & 106 & $66(60-78)$ & $60 \%$ & $9 \%$ & $31 \%$ & $12 \%$ & - & $3 \%$ & $76 \%$ & - & - & - & - \\
\hline Derman $^{51}$ & 2019 & Various & 192 & $>67(60-83)$ & $<50 \%$ & - & $40 \%$ & $7 \%$ & $22 \%$ & - & - & $?$ & $54 \%$ & - & - \\
\hline Dubruille $^{52}$ & 2015 & Various & 90 & $74(65-89)$ & $32 \%$ & $11 \%$ & $39 \%$ & $31 \%$ & $25 \%$ & $4 \%$ & $44 \%$ & - & $50 \%$ & $72 \%$ & $80 \%$ \\
\hline Dumontier $^{53}$ & 2019 & Various & 464 & $80(76-84)$ & $?$ & $11 \%$ & $27 \%$ & $?$ & - & - & - & - & - & - & - \\
\hline Hamaker $^{54}$ & 2016 & Various & 157 & $78(67-99)$ & $42 \%$ & $22 \%$ & $47 \%$ & $18 \%$ & $29 \%$ & $30 \%$ & - & $20 \%$ & $66 \%$ & - & $71 \%$ \\
\hline Huang $^{55}$ & 2020 & Various & 148 & $62(50-76)$ & $28 \%$ & - & $39 \%$ & $1 \%$ & $44 \%$ & $8 \%$ & - & $?$ & $50 \%$ & - & - \\
\hline $\operatorname{Lin}^{56}$ & 2020 & Various & 457 & $66(60-79)$ & $<47 \%$ & $4 \%$ & $11 \%$ & $44 \%$ & $18 \%$ & - & - & - & $50 \%$ & - & - \\
\hline $\mathrm{Liu}^{57}$ & 2019 & Various & 448 & $80(76-84)$ & $47 \%$ & - & - & $18 \%$ & - & $56 \%$ & - & - & - & - & $53 \%$ \\
\hline Muffly ${ }^{58}$ & 2014 & Various & 203 & $58(54-63)$ & $29 \%$ & $7 \%$ & $40 \%$ & - & - & $24 \%$ & - & - & - & - & $25 \%$ \\
\hline Nawas $^{59}$ & 2019 & Various & 184 & $61(50-75)$ & $1 \%$ & - & $36 \%$ & $3 \%$ & $35 \%$ & $15 \%$ & - & $?$ & - & - & - \\
\hline Rodrigues $^{60}$ & 2020 & Various & 40 & $68(60-76)$ & $75 \%$ & - & $10 \%$ & $21 \%$ & $18 \%$ & $16 \%$ & $43 \%$ & - & $80 \%$ & - & $19 \%$ \\
\hline Rollot-Trad ${ }^{6 !}$ & 2008 & Various & 54 & $86(75-99)$ & $56 \%$ & $39 \%$ & $51 \%$ & $27 \%$ & - & - & - & - & $39 \%$ & - & - \\
\hline Silay & 2015 & Various & 61 & 69 & $?$ & $21 \%$ & $26 \%$ & $26 \%$ & $34 \%$ & $16 \%$ & $27 \%$ & - & $51 \%$ & - & - \\
\hline Velghe $^{63}$ & 2014 & Various & 50 & 76 (70-87) & $?$ & $24 \%$ & $38 \%$ & $4 \%$ & $30 \%$ & - & $82 \%$ & - & - & $76 \%$ & $88 \%$ \\
\hline
\end{tabular}




\section{Discussion}

This systematic review of 44 studies shows that impairment in geriatric domains is common among older patients with a hematologic malignancy, even in those with a good performance status. The most relevant impairment is frailty (assessed with a frailty screening tool or by summarizing the geriatric assessment), which showed an association with mortality, treatment-related toxicity and treatment non-completion. Other relevant geriatric impairments were IADL functioning, nutritional status and polypharmacy. Impaired physical capacity was mainly associated with healthcare utilization.

These data should, however, be interpreted with care. The included studies are heterogeneous in study population, design, treatment regimens, content of geriatric assessment and reported outcomes. Various hematologic malignancies can have very different disease courses and

Table 3. The association of geriatric assessment, age, performance status, and comorbidity with mortality.

\begin{tabular}{|c|c|c|c|c|c|c|c|c|c|c|c|c|c|c|c|c|}
\hline $\begin{array}{l}\text { Publication } \\
\text { Author }\end{array}$ & Year & $\begin{array}{l}\text { Number } \\
\text { of patients }\end{array}$ & $\begin{array}{l}\text { Type of } \\
\text { malignancy }\end{array}$ & Age & PS & Comorbidity & ADL & $\mathrm{IADL}^{\mathrm{R}}$ & $\begin{array}{l}\text { Cesults of uI } \\
\text { Cognition }\end{array}$ & $\begin{array}{l}\text { nivariat } \\
\text { Mood }\end{array}$ & $\begin{array}{l}\text { and multi } \\
\text { Physical } \\
\text { capacity }\end{array}$ & $\begin{array}{c}\text { Ivariate analy } \\
\text { Nutritional } \\
\text { status }\end{array}$ & $\begin{array}{l}\text { ysis } \\
\text { Social } \\
\text { support }\end{array}$ & Polypharmac & $\begin{array}{l}\text { cy Fraility } \\
\text { screening } \\
\text { tool }\end{array}$ & $\begin{array}{l}\text { Summarized } \\
\text { g CA score }\end{array}$ \\
\hline Corsetti ${ }^{20}$ & 2011 & 31 & AML; RAEB & & & & & - & & & & & & & & - \\
\hline Deschler ${ }^{21}$ & 2013 & 195 & AML; MDS & -- & ++ & ++ & ++ & -- & -- & - & -- & & & & & \\
\hline Klepin $^{23}$ & 2013 & 74 & AML & -- & -- & -- & -- & - - & ++ & -- & ++ & & & & & \\
\hline Klepin $^{24}$ & 2020 & 40 & AML (FLT3) & & - & - & - & - & - & - & - & & - & - & & \\
\hline Molga ${ }^{25}$ & 2020 & 98 & AML; MDS & & - - & ++ & ++ & ++ & -- & - - & - - & -- & & & & \\
\hline Umit $^{27}$ & 2018 & 372 & AML & + & + & & & & & & & & & & + & \\
\hline Goede $^{28}$ & 2016 & 75 & CLL & -- & & - & & - & -- & & - - & & & & & \\
\hline Molica ${ }^{29}$ & 2019 & 108 & CLL & ++ & + & ++ & ++ & + & & & & & & & & ++ \\
\hline $\operatorname{Ribi}^{30}$ & 2017 & 41 & $\begin{array}{c}\text { B-cell } \\
\text { lymphoma }\end{array}$ & & & - & & & - & - & & + & - & & & + \\
\hline Ong ${ }^{32}$ & 2019 & 205 & DLBCL & & & & & & & & & & & & & ++ \\
\hline Spina $^{33}$ & 2012 & 100 & DLBCL & & & & -- & -- & & & & & & & & ++ \\
\hline Tucci $^{34}$ & 2009 & 84 & DLBCL & & & & & & & & & & & & & + \\
\hline Tucci $^{35}$ & 2015 & 173 & DLBCL & + & & + & + & + & & & & & & & & ++ \\
\hline Aaldriks $^{36}$ & 2015 & 44 & NHL & & & & & & & 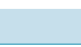 & & - & & & ++ & \\
\hline Naito $^{37}$ & 2016 & 93 & NHL & - & - & ++ & - & + & ++ & - & & - & & & & \\
\hline Park $^{38}$ & 2015 & 70 & NHL & & -- & & & & - & - & & ++ & & & - & \\
\hline Soubeyran $^{40}$ & 2011 & 32 & NHL & & & & + & + & + & + & & & & & & \\
\hline Winkelmann $n^{41}$ & 2011 & 143 & NHL & -- & -- & -- & -- & ++ & & & & & & & & \\
\hline Engelhardt ${ }^{43}$ & 2016 & 125 & MM & + & & ++ & & & & & & & & & ++ & \\
\hline Gavriatopoulou ${ }^{4}$ & 2019 & 110 & MM & & & & & & & & & & & & -- & \\
\hline Palumbo ${ }^{45}$ & 2015 & 869 & MM & ++ & & -- & ++ & ++ & & & & & & & & \\
\hline Zhong ${ }^{48}$ & 2017 & 628 & MM & -- & & -- & -- & -- & & & & & & & & - \\
\hline Buckstein $^{49}$ & 2016 & 445 & Various & + & + & ++ & & + & & & + & & & & ++ & \\
\hline Deschler $^{50}$ & 2018 & 106 & Various & ++ & ++ & - & & - & & & + & - & & & & \\
\hline Dubruille ${ }^{52}$ & 2015 & 90 & Various & ++ & -- & - & & & ++ & & - & - & & - & - & - \\
\hline Dumontier $^{53}$ & 2019 & 452 & Various & -- & & -- & -- & ++ & & & & & & & & \\
\hline Hamaker $^{54}$ & 2016 & 157 & Various & -- & -- & -- & & & & & & & & & & ++ \\
\hline Huang $^{55}$ & 2020 & 148 & Various & & - & & & ++ & - & & & & & & & \\
\hline $\operatorname{Lin}^{56}$ & 2020 & 457 & Various & + & ++ & -- & & ++ & & & & & & & & \\
\hline $\mathrm{Liv}^{57}$ & 2019 & 448 & Various & ++ & & & & & ++ & & ++ & & & & & \\
\hline Muffly $^{58}$ & 2014 & 203 & Various & ++ & - & ++ & - & ++ & & & ++ & & & & & \\
\hline Nawas ${ }^{59}$ & 2019 & 184 & Various & & -- & & & ++ & & & & & + & & & \\
\hline Rollot-Trad ${ }^{61}$ & 2008 & 54 & Various & -- & -- & & -- & - - & -- & & & & & & & \\
\hline \multicolumn{4}{|c|}{$\begin{array}{l}\text { Proportion of studies with a significant } \\
\text { association in univariate analysis }\end{array}$} & $79 \%$ & $63 \%$ & $64 \%$ & $67 \%$ & $74 \%$ & $55 \%$ & $14 \%$ & $63 \%$ & $33 \%$ & $33 \%$ & $0 \%$ & $71 \%$ & $67 \%$ \\
\hline \multicolumn{4}{|c|}{$\begin{array}{l}\text { Proportion of studies with a significant } \\
\text { association in multivariate analysis }\end{array}$} & $43 \%$ & $27 \%$ & $47 \%$ & $40 \%$ & $62 \%$ & $50 \%$ & $0 \%$ & $50 \%$ & $50 \%$ & $\mathrm{NA}$ & NA & $75 \%$ & $100 \%$ \\
\hline
\end{tabular}

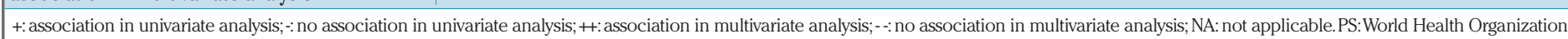

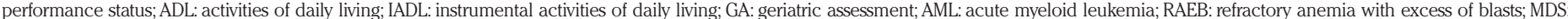
myelodysplastic syndrome; FLT3: FMS-like tyrosine kinase-3; CLL: chronic lymphocytic leukemia; DLBCL: diffuse large B-cell lymphoma; NHL: non-Hodgkin lymphoma; MM: multiple myeloma. 
require very different intensities of treatment; geriatric impairments that were associated with outcome in one setting may not retain their predictive value in another disease entity. In addition, the content of geriatric assessments, including the definition of frailty (assessed by summarizing the geriatric assessment), was not consistent. Moreover, geriatric impairments were mainly assessed with screening tools (for example, the Mini-Mental State Examination for cognition), and it should be realized that the ensuing results are not the same as an actual diagnosis made by a comprehensive geriatric assessment. Given this heterogeneity, a meta-analysis or a meaningful subgroup analysis (for example, by type of malignancy) could not be performed; and interpretation and extrapolation of results should be done with caution. Another limitation of this review is the procedure used to select the literature. We decided to select only those studies for which a full text is available and which performed a geriatric assessment with validated tools covering at least two geriatric domains. Studies which focused on a single impairment and its relation to outcome were not included, meaning some information on individual associations may have been missed.

Despite these limitations, this review provides a thorough update and overview of all currently available evidence on the relevance of a geriatric assessment for older patients with a hematologic malignancy. At the time of the previous systematic review, by Hamaker et al., ${ }^{17}$ the evidence was limited because of a lack of published studies. In the last 5 years, the number of publications concerning the association of geriatric assessment with outcomes in patients with hematologic malignancies has increased greatly, enabling a useful update on the available data.

Performing a geriatric assessment could have an additive value to clinical judgment, treatment allocation and the implementation of non-oncological interventions.

In daily practice, oncologists are able to detect obviously frail patients by clinical judgment. However, estimating the reserve capacity and resilience of the remaining older patients by clinical judgment is difficult, as demonstrated by the discrepancy between performance status and geriatric assessment. In addition, it can be challenging to distinguish whether the detected vulnerabilities are diseaserelated or patient-related. This may require a more thorough evaluation of the patient's overall health status, including consultation of a geriatrician.

The impact of performing a geriatric assessment on treatment allocation has already been demonstrated in older patients with solid malignancies. ${ }^{73,74}$ In a systematic review, the oncological treatment plan was altered in $28 \%$ of patients after geriatric assessment, primarily resulting in a less intensive treatment option. This review showed that using a geriatric assessment to guide treatment decisions appeared to have a positive effect on clinical outcome, resulting in less treatment-related toxicity, fewer complications, and increased treatment completion. ${ }^{75}$ For example, in patients with cognitive impairments, treatment decisions should be made with great care because of the higher risk of chemotherapy-related progression of cognitive dysfunction, treatment non-compliance and death. ${ }^{52,71}$

In order to tailor cancer treatment to individual needs, it could be interesting to incorporate patient-reported outcome measures (PROMS) into the treatment decision-making process. PROMS, such as physical functioning and quality of life during and after treatment, were hardly assessed in the studies included in this review, despite quality of life being of primary importance to many older patients. ${ }^{76}$ It is, therefore, highly relevant that future studies address the association between geriatric impairments and PROMS. ${ }^{77}$

In addition to clinical judgment and treatment allocation, a geriatric assessment can be used to introduce non-oncological interventions before and during treatment in the hope of improving the patient's health status, resilience and treatment tolerance. However, evidence concerning the effectiveness of such non-oncological interventions is limited. Previous research suggests that perhaps physiotherapy $^{78,79}$ as well as nutritional counseling ${ }^{80-82}$ can improve survival, physical functioning and quality of life. Nononcological interventions in older patients undergoing chemotherapy can improve treatment completion and treatment modifications. ${ }^{83}$ The process by which a patient's condition can be enhanced before starting treatment is called prehabilitation. Although results of the first studies assessing the effectiveness of prehabilitation in patients with solid malignancies are promising, ${ }^{84,85}$ the level of evidence is weak, making it too early to draw definitive conclusions. Currently, according to clinicaltrials.gov (searched February 5, 2020), there are 29 ongoing trials in which the effect of non-oncological interventions on clinical outcome measures in older cancer patients is being assessed; six out of these 29 trials focus on hematologic malignancies. ${ }^{86}$ Based on these numbers, further data will follow in the coming years.

In conclusion, this review demonstrates the relevance of performing a geriatric assessment in older patients with a hematologic malignancy. Although the results should be interpreted and extrapolated carefully, our review shows that even in patients with a good performance status, a geriatric assessment can detect geriatric impairments that might be predictive of mortality. Moreover, geriatric impairments seem to be associated with a higher risk of treatment-related toxicity, treatment non-completion and utilization of healthcare services. Future research is needed to extend these findings with a focus on reserve capacity, resilience, quality of life and the effectiveness of nononcological interventions.

\section{References}

1. Smith A, Howell D, Patmore R, Jack A, Roman E. Incidence of haematological malignancy by sub-type: a report from the Haematological Malignancy Research Network. Br J Cancer. 2011;105(11):16841692.
2. National Cancer Institute. Cancer Stat Facts [Internet]. [cited 2019 Jul 21]. Available from: https://seer.cancer.gov

3. Bron D, Ades L, Fulop T, Goede V, Stauder R. Aging and blood disorders: new perspectives, new challenges. Haematologica. 2015;100(4):415-417.

4. Warren JL, Harlan LC, Stevens J, Little RF, Abel GA. Multiple myeloma treatment transformed: a population-based study of changes in initial management approaches in the United States. J Clin Oncol. 2013;31(16):1984-1989.

5. Abel GA, Koreth J. Optimal positioning of hematopoietic stem cell transplantation for older patients with myelodysplastic syndromes. Curr Opin Hematol. 2013;20(2): 150-156. 
6. McClune BL, Weisdorf DJ, Pedersen TL, et al. Effect of age on outcome of reducedintensity hematopoietic cell transplantation for older patients with acute myeloid leukemia in first complete remission or with myelodysplastic syndrome. J Clin Oncol. 2010;28(11):1878-1867.

7. Hamaker ME, Stauder R, van Munster BC. Exclusion of older patients from ongoing clinical trials for hematological malignancies: an evaluation of the National Institutes of Health clinical trial registry. Oncologist. 2014;19(10):1069-1075

8. Extermann M, Aapro M, Bernabei R, et al. Use of comprehensive geriatric assessment in older cancer patients: recommendations from the task force on CGA of the International Society of Geriatric Oncology (SIOG). Crit Rev Oncol Hematol. 2005;55(3):241-225.

9. Gobbens RJ, Luijkx KG, Wijnen-Sponselee MT, Schols JM. Toward a conceptual definition of frail community dwelling older people. Nurs Outlook. 2010;58(2):76-86.

10. Fried LP, Tangen CM, Walston J, et al. Frailty in older adults: evidence for a phenotype. J Gerontol A Biol Sci Med Sci. 2001;56(3):146156

11. Mitnitski AB, Mogilner AJ, Rockwood K. Accumulation of deficits as a proxy measure of aging. ScientificWorldJournal. 2001;8(1): 323-336

12. Rockwood K, Song X, MacKnight C, et al. A global clinical measure of fitness and frailty in elderly people. CMAJ. 2005;173(5):489495.

13. Mohile SG, Dale W, Somerfield MR, et al. Practical assessment and management of vulnerabilities in older patients receiving chemotherapy: ASCO guideline for geriatric oncology. J Clin Oncol. 2018;36(22):23262347.

14. Wildiers $H$, Heeren P, Puts $M$, et al. International society of geriatric oncology consensus on geriatric assessment in older patients with cancer. J Clin Oncol. 2014;32(24):2595-2601

15. van Walree IC, Scheepers E, van Huis-Tanja $\mathrm{LH}$, et al. A systematic review on the association of the G8 with geriatric assessment, prognosis and course of treatment in older patients with cancer. J Geriatr Oncol. 2019;10(6):847-858.

16. Goede V, Stauder R. Multidisciplinary care in the hematology clinic: implementation of geriatric oncology. J Geriatr Oncol. 2019;10(3):497-503.

17. Hamaker ME, Prins MC, Stauder R. The relevance of a geriatric assessment for elderly patients with a haematological malignancy a systematic review. Leuk Res. 2014;(38): 275-283.

18. Wells GA, Shea B, O'Connell D, et al. The Newcastle-Ottawa Scale (NOS) for assessing the quality of nonrandomised studies in meta-analyses. Ottawa Hospital Research Institute, 2012

19. Aguiar APN, Mendonça P da S, RibeiroJúnior HL, et al. Myelodysplastic syndromes: an analysis of non-hematological prognostic factors and its relationship to age. J Geriatr Oncol. 2020;(11):125-127.

20. Corsetti MT, Salvi F, Perticone S, et al. Hematologic improvement and response in elderly AML/RAEB patients treated with valproic acid and low-dose Ara-C. Leuk Res. 2011;35(8):991-997.

21. Deschler B, Ihorst G, Platzbecker U, et al. Parameters detected by geriatric and quality of life assessment in 195 older patients with myelodysplastic syndromes and acute myeloid leukemia are highly predictive for outcome. Haematologica. 2013;98(2):208216.

22. Holmes H, Des Bordes IKA, Kebriaei P, et al Optimal screening for geriatric assessment in older allogeneic hematopoietic cell transplantation candidates. J Geriatr Oncol. 2014;5(4):422-430.

23. Klepin HD, Geiger AM, Tooze JA, et al Geriatric assessment predicts survival for older adults receiving induction chemotherapy for acute myelogenous leukemia. Blood. 2013:121(21):4287-4294.

24. Klepin HD, Ritchie E, Major-Elechi B, et al. Geriatric assessment among older adults receiving intensive therapy for acute myeloid leukemia: report of CALGB 361006 (Alliance). J Geriatr Oncol. 2020;(11):107113.

25. Molga A, Wall M, Chhetri R, et al Comprehensive geriatric assessment predicts azacitidine treatment duration and survival in older patients with myelodysplastic syndromes. J Geriatr Oncol. 2020;(11):114 120.

26. Molga A, Wall M, Wee LYA, et al. Screening for deficits using the G8 and VES-13 in older patients with myelodysplastic syndromes. J Geriatr Oncol. 2020;(11):128-130.

27. Umit EG, Baysal M, Demir AM. Frailty in patients with acute myeloid leukaemia, conceptual misapprehension of chronological age. Eur J Cancer Care (Engl). 2018;27(2): e12810.

28. Goede V, Bahlo J, Chataline V, et al. Evaluation of geriatric assessment in patients with chronic lymphocytic leukemia: results of the CLL9 trial of the German CLL study group. Leuk Lymphoma. 2016:57(4):789-796

29. Molica S, Giannarelli D, Levato L, et al. A simple score based on geriatric assessment predicts survival in elderly newly diagnosed chronic lymphocytic leukemia patients. Leuk Lymphoma. 2019;60(3):845-847.

30. Ribi K, Rondeau S, Hitz F, et al. Cancer-specific geriatric assessment and quality of life: important factors in caring for older patients with aggressive B-cell lymphoma. Support Care Cancer. 2017;25(9):2833-2842.

31. Merli F, Cavallo F, Salvi F, et al. Obinutuzumab and miniCHOP for unfit patients with diffuse large B-cell lymphoma. A phase II study by Fondazione Italiana Linfomi. J Geriatr Oncol. 2020;(11):37-40.

32. Ong DM, Ashby M, Grigg A, et al Comprehensive geriatric assessment is useful in an elderly Australian population with diffuse large B-cell lymphoma receiving rituximab-chemotherapy combinations. Br J Haematol. 2019;(187):73-81.

33. Spina $M$, Balzarotti $M$, Uziel $L$, et al. Modulated chemotherapy according to modified comprehensive geriatric assessment in 100 consecutive elderly patients with diffuse large B-cell lymphoma. Oncologist. 2012;17(6):838-846.

34. Tucci A, Ferrari S, Bottelli C, Borlenghi E, Drera M, Rossi G. A comprehensive geriatric assessment is more effective than clinical judgment to identify elderly diffuse large cell lymphoma patients who benefit from aggressive therapy. Cancer. 2009;115(19): 4547-4553.

35. Tucci A, Martelli M, Rigacci L, et al. Comprehensive geriatric assessment is an essential tool to support treatment decisions in elderly patients with diffuse large B-cell lymphoma: a prospective multicenter evaluation in 173 patients by the Lymphoma Italian Foundation (FIL). Leuk Lymphoma.
2015;56(4):921-926

36. Aaldriks A, Giltay E, Nortier J, et al. Prognostic significance of geriatric assessment in combination with laboratory parameters in elderly patients with aggressive non-Hodgkin lymphoma. Leuk Lymphoma. 2015;56(4):927-935.

37. Naito Y, Sasaki H, Takamatsu Y, Kiyomi F Tamura K. Retrospective analysis of treatment outcomes and geriatric assessment in elderly malignant lymphoma patients. J Clin Exp Hematop. 2016;56(1):43-49.

38. Park S, Hong J, Hwang I, et al. Comprehensive geriatric assessment in elderly patients with newly diagnosed aggressive non-Hodgkin lymphoma treated with multi-agent chemotherapy. J Geriatr Oncol. 2015;6(6):470-478.

39. Siegel AB, Lachs M, Coleman M, Leonard JP. Lymphoma in elderly patients: novel functional assessment techniques provide better discrimination among patients than traditional performance status measures. Clin Lymphoma Myeloma. 2006;7(1):65-69.

40. Soubeyran P, Khaled H, MacKenzie M, et al Diffuse large B-cell and peripheral T-cell non-Hodgkin's lymphoma in the frail elderly. A phase II EORTC trial with a progressive and cautious treatment emphasizing geriatric assessment. J Geriatr Oncol. 2011;2(1):36-44

41. Winkelmann N, Petersen I, Kiehntopf M, Fricke HJ, Hochhaus A, Wedding U. Results of comprehensive geriatric assessment effect survival in patients with malignant lymphoma. J Cancer Res Clin Oncol 2011:137(4):733-738.

42. Okuyama $T$, Sugano K, Iida $S$, Ishida $T$, Kusumoto S, Akechi T. Screening performance for frailty among older patients with cancer: a cross-sectional observational study of two approaches. J Natl Compr Cancer Netw. 2015;13(12):1525-1531.

43. Engelhardt M, Dold SM, Ihorst G, et al Geriatric assessment in multiple myeloma patients: Validation of the International Myeloma Working Group (IMWG) score and comparison with ther common comorbidity scores. Haematologica. 2016;101(9): 1110-1119.

44. Gavriatopoulou M, Fotiou D, Koloventzou $\mathrm{U}$, et al. Vulnerability variables among octogenerian myeloma patients: a single-center analysis of 110 patients. Leuk Lymphoma. 2019;60(3):619-628.

45. Palumbo A, Bringhen S, Mateos MV, et al Geriatric assessment predicts survival and toxicities in elderly myeloma patients: an International Myeloma Working Group report. Blood. 2015;125(13):2068-2074

46. Rosko AE, Huang Y, Benson DM, et al. Use of a comprehensive frailty assessment to predict morbidity in patients with multiple myeloma undergoing transplant. J Geriatr Oncol. 2019;10(3):479-85

47. Wildes TM, Tuchman SA, Klepin HD, et al. Geriatric assessment in older adults with multiple myeloma. J Am Geriatr Soc 2019;67(5):987-991

48. Zhong YP, Zhang YZ, Liao AJ, Li SX, Tian C $\mathrm{Lu} \mathrm{J}$. Geriatric assessment to predict survival and risk of serious adverse events in elderly newly diagnosed multiple myeloma patients: A multicenter study in China. Chin Med J (Engl). 2017;130(2):130-134

49. Buckstein R, Wells RA, Zhu N, et al. Patientrelated factors independently impact overall survival in patients with myelodysplastic syndromes: an MDS-CAN prospective study. Br J Haematol. 2016;174(1):88-101.

50. Deschler B, Ihorst G, Schnitzler S, Bertz H, 
Geriatric assessment in older patients with a hematologic malignancy

Fink J. Geriatric assessment and quality of life in older patients considered for allogeneic hematopoietic cell transplantation: a prospective risk factor and serial assessment analysis article. Bone Marrow Transplant. 2018;53(5):565-575.

51. Derma BA, Kordas K, Ridgeway J, et al. Results from a multidisciplinary clinic quided by geriatric assessment before stem cell transplantation in older adults. Blood Adv. 2019;3(22):3488-3498.

52. Dubruille $S$, Liber $Y$, Kos $M$, et al. Identification of clinical parameters predicfive of one-year survival using two geriatric tools in clinically fit older patients with hematological malignancies: major impact of cognition. J Geriatr Oncol. 2015;6(5):362369.

53. DuMontier C, Lu MA, Murillo A, et al. Function, survival, and care utilization among older adults with hematologic malignancies. J Am Geriatr Soc. 2019;(67):889897.

54. Hamaker ME, Augschoell J, Stauder R. Clinical judgement and geriatric assessment for predicting prognosis and chemotherapy completion in older patients with a hematological malignancy. Leek Lymphoma. 2016;57(11):2560-2567.

55. Huang LW, Shend Y, Andreadis C, et al. Functional status as measured by geriatric assessment predicts inferior survival in older allogeneic hematopoietic cell transplantatron recipients: functional status predicts post-alloHCT survival. Biol Blood Marrow Transplant. 2020;(26):189-196.

56. Lin RJ, Elko TA, Devin SM, et al. Impact of geriatric vulnerabilities on allogeneic hematopoietic cell transplantation outcomes in older patients with hematologic malignancies. Bone Marrow Transplant. 2020;(55):157-164.

57. Lu MA, DuMontier C, Murillo A, et al. Gait speed, grip strength, and clinical outcomes in older patients with hematologic malignancies. Blood. 2019;134(4):374-382.

58. Muffly LS, Kocherginsky M, Stock W, et al. Geriatric assessment to predict survival in older allogeneic hematopoietic cell transplantation recipients. Haematological. 2014;99(8):1373-1379.

59. Nawas MT, Andreadis C, Martin TG, et al. Limitation in patient-reported function Is associated with inferior survival in older adults undergoing autologous hematopoietic cell transplantation. Biol Blood Marrow Transplant. 2019;25(6):1218-1224.

60. Rodrigues M, de Sousa PMR, de Oliveira Muniz Koch L, Hamerschlak N. The use of comprehensive geriatric assessment in older patients before allologeneic hematopoietic stem cell transplantation: a cross-sectional study. J Geriatr Oncol. 2020;(11):100-106.

61. Rollot-Trad F, Lahjibi H, Lazarovici C, Bauer C, Saint-Jean O, Gisselbrecht M. Haematological malignancies in older adults: experience in a geriatric acute care department. Rev Med Interne. 2008;29(7): 541-549.

62. Silly K, Akinci S, Silly YS, et al. Hospitalization risk according to geriatric assessment and laboratory parameters in elderly hematologic cancer patients. Asian Pacific J Cancer Prev. 2015;16(2):1783-1786.

63. Velghe A, Petrovic M, De Buyser S, Demuynck R, Noens L. Validation of the G8 screening tool in older patients with aggressrive haematological malignancies. Eur J Oncol Nurs. 2014;18(6):645-648.

64. Klepin HD, Geiger AM, Doze JA, et al. The feasibility of inpatient geriatric assessment for older adults receiving induction chemotherapy for acute myelogenous leukemia. J Am Geriatr Soc. 2011;59(10): 1837-1846

65. Klepin HD, Tooze JA, Pardee TS, et al. Effect of intensive chemotherapy on physical, cogunitive, and emotional health of older adults with acute myeloid leukemia. J Am Geriatr Soc. 2016;64(10):1988-1995.

66. Isaacs A, Fiala M, Tuchman S, Wides TM. A comparison of three different approaches to defining frailty in older patients with multiale myeloma. J Geriatr Oncol. 2020;11(2):311-315.

67. Hamaker ME, Mitrovic M, Stander R. The G8 screening tool detects relevant geriatric impairments and predicts survival in elderly patients with a haematological malignancy. Ann Hematol. 2014;93(6):1031-1040.

68. Hofer F, Koinig KA, Nail L, Borjan B, Stander $R$. Fatigue at baseline is associated with geratric impairments and represents an adverse prognostic factor in older patients with a hematological malignancy. Ann Hematol. 2018;97(11):2235-2243.

69. Lin RJ, Shahrokni A, Dahi PB, et al. Pretransplant comprehensive geriatric assessment in hematopoietic cell transplantalion: a single center experience. Bone Marrow Transplant. 2018;53:1184-1187.

70. Lin RJ, Dahi PB, Shahrokni A, et al. Feasibility of a patient-reported, electronic geriatric assessment tool in hematopoietic cell transplantation-a single institution pilot study. Leak Lymphoma. 2019;60(13):33083311.

71. Hshieh TT, Jung WF, Grands LJ, et al. Prevalence of cognitive impairment and association with survival among older patients with hematologic cancers. JAMA Oncol. 2018;4(5):686-693.

72. Muffly LS, Boulukos M, Swanson K, et al. Pilot study of comprehensive geriatric assessment (CGA) in allogeneic transplant: CGA captures a high prevalence of vulnerabilities in older transplant recipients. Biol Blood Marrow Transplant. 2013;19(3):429434.

73. Gore R, Greillier L, Le Caër H, et al. Use of a comprehensive geriatric assessment for the management of elderly patients with advanced non-small cell lung cancer: the phase III randomized ESOGIA-GFPC-GECP
08-02 study. J Chin Oncol. 2016;34(13):14761483.

74. Kirkhus L, Benth JŠ, Rostoft S, et al. Geriatric assessment is superior to oncologists' clinecal judgement in identifying frailty. $\mathrm{Br} \mathrm{J}$ Cancer. 2017;117(4):470-477.

75. Hamaker ME, te Molder M, Thielen N, van Munster BC, Schiphorst AH, van His LH. The effect of a geriatric evaluation on treatmont decisions and outcome for older cancen patients - a systematic review. J Geriatr Oncol. 2018;9(5):430-440.

76. Van Leeuwen KM, Van Loon MS, Van Nee FA, et al. What does quality of life mean to older adults? A thematic synthesis. PLoS One. 2019;14(3):1-39.

77. Staider R, Lambert J, Desruol-Allardin S, et al. Patient-reported outcome measures in studies of myelodysplastic syndromes and acute myeloid leukemia: literature review and landscape analysis. Eur J Haematol. 2020 Jan 27. [Epub ahead of print]

78. Meneses-Echávez JF, González-Jiménez E, Ramírez-Vélez R. Supervised exercise reduces cancer-related fatigue: a systematic review. J Physiother. 2015;61(1):3-9.

79. Buffart LM, Kalter J, Sweegers MG, et al. Effects and moderators of exercise on quaity of life and physical function in patients with cancer: an individual patient data metaanalysis of 34 RETs. Cancer Treat Rev. 2017;52:91-104.

80. Baldwin C, Spiro A, Ahern R, Emery PW. Oral nutritional interventions in malnourished patients with cancer: a systematic review and meta-analysis. J Natl Cancer Inst. 2012;104(5):371-385.

81. Schultz P, Fer R, Baechli V, et al. Individualised nutritional support in medical inpatients at nutritional risk: a randomised clinical trial. Lancet. 2019;393(10188):23122321.

82. Caillet P, Leu E, Reynaud Simon A, et al. Association between cachexia, chemotheraby and outcomes in older cancer patients: a systematic review. Chin Nutr. 2017;36:14731482.

83. Kali T, Babic-Illman G, Ross PJ, et al. The impact of comprehensive geriatric assessmont interventions on tolerance to chemotherapy in older people. Br J Cancer. 2015;112(9):1435-1444.

84. Buns ERJ, van den Heuvel B, Buskens CJ, et al. The effects of physical prehabilitation in elderly patients undergoing colorectal surgary: a systematic review. Color Dis. 2016;18(8):267-277.

85. Driessen EJ, Peters ME, Bongers BC, et al. Effects of rehabilitation and rehabilitation including a home-based component on physical fitness, adherence, treatment toleonce, and recovery in patients with nonsmall cell lung cancer: a systematic review. Crit Rev Oncol Hematol. 2017;114:63-76.

86. ClinicalTrials.gov. U.S. National Library of Medicine [Internet]. [cited 2020 Feb 5]. Available from: https://clinicaltrials.gov/

haematological | 2020; 105(6)

1493 